\title{
Ophthalmology in the Oxford Region: Analysis of Time Trends From Linked Statistics
}

\author{
J. A. FERGUSON, M. J. GOLDACRE, J. HENDERSON, A. J. BRON \\ Oxford
}

Summary

Objectives: to report on trends in ophthalmology workload using linked statistical data;

Design: analysis of linked abstracts of hospital inpatient and day case records for ophthalmology;

Setting: six districts in Southern England covered by the Oxford record linkage study;

Subjects: records for hospital admissions to ophthalmology from 1975 to 1985;

Measurement and Main Results: Over the period of study, the number of episodes of inpatient and day case care increased by $16.3 \%$. Notable increases in age-specific admission rates were seen among the elderly. An increase in the number of individuals treated contributed about $67 \%$ and an increase in multiple admissions per individual contributed about $33 \%$ to the increase in admission rates. Both average length of stay per episode and total time in hospital per individual decreased consistently during the 11 years; and there was no increase in emergency readmissions over time. No significant changes over time were found in admission rates for retinal detachments and defects or for glaucoma. There was a statistically significant increase averaging $4.8 \%$ per annum in admission rates for cataract, and a significant decrease averaging 5.2\% per annum in admission rates for strabismus and other disorders of binocular eye movement between 1975 and 1985.

Conclusions: Age-specific admission rates in ophthalmology are much higher in the very young and old than in other age groups. Patterns of work in the specialty are therefore particularly affected by variation in the age distribution of the population. The increase in cataract surgery reflected both the increase in numbers of old people in the population and an increase in age-specific operation rates for cataract. Attempts to alter attitudes and behaviour of the elderly regarding eye diseases, disability, and facilities for treatment may have had a positive impact on the use of services. The decrease in admissions for children probably reflects the impact made by child health surveillance programmes. As the child screening programme has expanded, the admission rates for strabismus have decreased.

Children with squints and old people with cataracts account for a substantial portion of the inpatient work of ophthalmologists. It is therefore a specialty which is particularly sus- ceptible to shifts in the demographic profile of the population it serves. ${ }^{1}$ The number of elderly people in the population is growing, especially the very elderly aged over 85 years

From: Unit of Clinical Epidemiology, Department of Public Health and Primary Care, University of Oxford and Department of Ophthalmology, University of Oxford.

Correspondence to Dr. Joyce Ferguson, Unit of Clinical Epidemiology, Oxford Regional Health Authority, Old Road, Headington, Oxford OX3 7LF. 
for whom an increase of $43 \%$ is expected in the Oxford Region between 1990 and 2000. ${ }^{2}$ The number of children in the population tends to fluctuate substantially with contemporary birth rates. In the Oxford Region, the overall projected growth from 1990 to 2000 in the $0-4$ age group is $8 \%$, but this proportion varies between the districts from a $9 \%$ decrease to a $39 \%$ increase. $^{2}$ With demographic changes, technological advances, the emergence of child health surveillance, and attempts to improve the underutilisation of ophthalmic services by the elderly, ${ }^{3,4}$ changes in workload in ophthalmology may be expected.

Routinely collected statistics show that there has been a consistent rise in hospital admission rates across all specialties in the acute sector of about $2 \%$ annually in England. ${ }^{5}$ There are limitations, however, in using routine information systems in the National Health Service to understand patterns of workload because routine data are episode-based and unlinked: thus two or more admissions for the same individual cannot be distinguished. The Oxford record linkage study has been used to relate workload statistics to the care of individuals by linking together episodes of care for the same individual. ${ }^{6} \mathrm{~A}$ series of studies is being undertaken, one in each specialty, to assess trends in workload using these linked data. In this paper we describe trends in hospital admission and readmission rates, lengths of stay, and clinical caseload in ophthalmology.

\section{Material and methods}

The Oxford record linkage study is a collection of abstracts of hospital inpatient records (including day cases) together with data from birth registrations and death certificates. The data are collected in such a way that records can be linked. ${ }^{6}$ The analyses presented here relate to residents of six districts of the Oxford Regional Health Authority covered by data collection between 1975-1985.

First, we analysed trends in episode-based and person-based admission rates to ophthalmology. Second, we analysed patterns of readmission for individuals discharged from ophthalmology. A readmission was defined as the first subsequent hospital episode (exclud- ing transfers) to any specialty for a patient within 28 days of discharge from ophthalmology. The method used has been discussed elsewhere. ${ }^{7}$ Third, average lengths of stay and total days spent in hospital by each individual in each year in ophthalmology were calculated. The latter calculation was based on the sum of the lengths of stay of all the ophthalmology episodes experienced by an individual in the calendar year. Finally, the clinical caseload of the specialty is described using diagnoses based on the Eighth and Ninth Revisions of the International Classification of Diseases. ${ }^{8,9}$ Chi square tests for trend were used to test the significance of changes over time.

\section{Results}

Person-based admission rates for each age group in 1975 and 1985 are shown in Figure 1. The patterns for males and females were similar. The age distribution is strikingly bimodal-higher rates for the young and old than for others-and the elderly experienced the highest admission rates of all age groups throughout the time period. There was a substantial increase in person-based admission rates between 1975 and 1985 in both sexes for those over 60 years of age.

Episode-based and person-based admission rates were compared and the mean numbers of episodes per person in each year are shown in Table I. No important differences were found between males and females. The data in Table I show the extent to which routine episode-based health service statistics are inflated by multiple counting of successive episodes for the same person in ophthalmology. For example, in 1975, there was a total of 3,527 admissions for 3,180 people, while in 1985 , there was a total of 4,102 admissions for 3,564 people. Thus the number of people admitted to hospital in ophthalmology increased by $12.1 \%$, and the number of episodes of hospital care increased by $16.3 \%$ during the eleven year period.

In Table II, two measures of time spent in hospital are presented. The conventional measure, that of average length of stay per episode, is shown and compared with the total time in hospital per individual taking account of multiple episodes per person. A consistent 


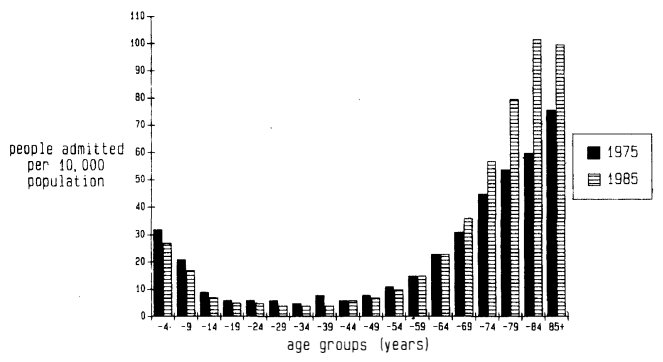

Table for Figure 1: Person-based hospital admission rates for males in Oxford Region for Ophthalmology (persons per 10,000 population)

\begin{tabular}{crr}
\hline Age & 1975 & 1985 \\
\hline $0-4$ & 32 & 27 \\
$5-9$ & 21 & 17 \\
$10-14$ & 9 & 7 \\
$15-19$ & 6 & 5 \\
$20-24$ & 6 & 5 \\
$25-29$ & 6 & 4 \\
$30-34$ & 5 & 4 \\
$35-39$ & 8 & 4 \\
$40-44$ & 6 & 6 \\
$45-49$ & 8 & 7 \\
$50-54$ & 11 & 10 \\
$55-59$ & 15 & 15 \\
$60-64$ & 23 & 23 \\
$65-69$ & 31 & 36 \\
$70-74$ & 45 & 57 \\
$75-79$ & 54 & 80 \\
$80-84$ & 60 & 102 \\
$85+$ & 76 & 100 \\
\hline
\end{tabular}

decrease throughout the eleven years in both measures was found.

Concern is sometimes expressed that falling lengths of stay in the health service might be accompanied by an increase in emergency readmissions. We therefore analysed the percentage of patients who experienced emergency admissions (to any specialty) within 28

Table I Average number of hospital admissions per person hospitalised in each year in 1975 and 1985

\begin{tabular}{ccc}
\hline $\begin{array}{c}\text { Age } \\
\text { Group }\end{array}$ & 1975 & 1985 \\
\hline $0-4$ & 1.12 & 1.08 \\
$5-9$ & 1.07 & 1.09 \\
$10-49$ & 1.11 & 1.11 \\
$50-64$ & 1.13 & 1.17 \\
$65-74$ & 1.12 & 1.20 \\
$75-79$ & 1.11 & 1.17 \\
$80-84$ & 1.02 & 1.19 \\
$85+$ & 1.07 & 1.15 \\
Total & 1.11 & 1.15 \\
\hline
\end{tabular}

days following discharge from hospital care in ophthalmology (Figure 2). There was no clear or consistent increase in emergency readmissions over time.

Trends between 1975 and 1985 in admission rates for the main diagnostic categories are shown in Table III. (For a full explanation of the terminology used, see Appendix.) All diagnostic categories in ophthalmology which occurred more frequently than in one person per 10,000 population per year have been included. In addition, data on retinal detachments and defects are also presented. The four groups of diagnoses described accounted for $65.3 \%$ of the total number of people admitted to ophthalmology. No significant changes over time were found in admission rates for retinal detachments and defects or for glaucoma. However, there was a significant increase in admission rates for cataract averaging $4.8 \%$ per annum and a significant decrease averaging $5.2 \%$ per annum in admission rates for strabismus and other disorders of binocular eye movements between 1975 and 1985.

\section{Discussion}

The availability of linked records means that patterns of hospital care can be analysed in relation both to episodes of hospital care and to individuals receiving such care. Both indices are important. The White Paper 'Working for Patients' has stressed the importance of measuring, auditing and contracting for workload. Managers and clinicians will be interested in episode-based

Table II Average lengths of stay in ophthalmology per episode and per person per year

\begin{tabular}{ccc}
\hline $\begin{array}{c}\text { Year } \\
\text { Admission }\end{array}$ & $\begin{array}{c}\text { Length of stay } \\
\text { per episode }\end{array}$ & $\begin{array}{c}\text { Total Days in } \\
\text { Hospital per person }\end{array}$ \\
\hline 1975 & 6.5 & 7.2 \\
1976 & 5.7 & 6.4 \\
1977 & 5.3 & 6.1 \\
1978 & 5.1 & 5.9 \\
1979 & 4.7 & 5.4 \\
1980 & 4.7 & 5.3 \\
1981 & 4.4 & 5.1 \\
1982 & 4.2 & 4.9 \\
1983 & 4.0 & 4.7 \\
1984 & 4.0 & 4.6 \\
1985 & 4.0 & 4.6 \\
Mean & 4.8 & 5.5 \\
\hline
\end{tabular}




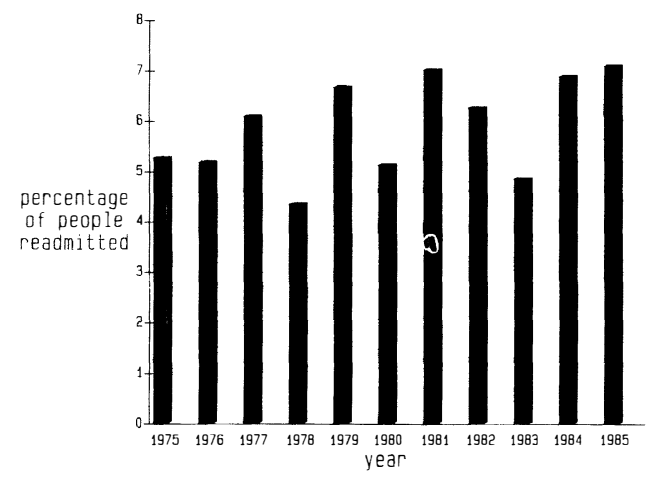

Table for Figure 2: Hospital emergency readmissions (to any specialty) within 28 days of an ophthalmology episode

\begin{tabular}{cc}
\hline Year & $\begin{array}{c}\text { number of emergency reads. } \\
\text { after an episode } \\
\text { as of all index events }\end{array}$ \\
\hline 1975 & 5.27 \\
1976 & 5.18 \\
1977 & 6.09 \\
1978 & 4.35 \\
1979 & 6.67 \\
1980 & 5.13 \\
1981 & 7.01 \\
1982 & 6.26 \\
1984 & 4.85 \\
1985 & 6.88 \\
\hline
\end{tabular}

patterns of admission as measures of 'units' of treatment. Clinicians and epidemiologists will be interest in the numbers of individual patients treated as measures of clinical practice and of the occurrence of treated disease. The introduction of the recommendations of the National Steering Group on Health Services Information, ${ }^{10}$ chaired by Mrs. E. Korner, will facilitate linkage of hospital records within districts (but not across districts) allowing statistics similar to those produced in this paper to be routinely analysed.

There were large increases in hospital admissions for the elderly in each age-group over 65 years between 1975 and 1985 (Fig. 1). Attempts to alter attitudes and behaviour of the elderly regarding eye diseases, disability, and facilities for treatment may have had a positive impact. These trends confirm the clinical impression that there has been a real rise in referrals of the elderly. Excellent optical correlation by surgical procedures is due, in part, to the success of modern lens implants. This provides a much more appealing result for an elderly patient who, previously, had to resort to spectacles with heavy lenses. Criteria for referral and surgery have altered and advanced the time of operating from the previous method of annual surveillance awaiting further visual deterioration. Also, anaesthetic techniques have become more sophisticated and, as a result, have become more suitable for the ageing patient.

The decrease in hospital admissions for children over the eleven year period probably reflects the impact made by child health surveillance programmes. The diagnosis of strabismus is being made earlier, and, as a result, treatment is focusing on outpatient refraction and occlusion therapy for ambylopia.

Speculation over the rise in episode-based rates of hospital admissions nationally has fuelled debate about whether, on the one hand, each year more people than ever have received hospital care; or, on the other hand, whether there has been an increase in multiple admissions per individual. In the case of ophthalmology in the Oxford region, an increase in the numbers of people treated contributed about $67 \%$ and an increase in multiple admissions per individual contributed about $33 \%$ to the increase in admissions. The data in Table II confirm that both length of stay per episode and the total number of days an individual stays in hospital each year have decreased in ophthalmology.

There has been general speculation in the health service that an increase in admission rates, a decline in numbers of available beds and a decline in lengths of stay may have resulted in an increase in emergency readmissions. It seems clear that emergency readmission rates in patients discharged from ophthalmology have not increased in the Oxford Region.

The decrease seen in admission rates for strabismus can be partially explained by the establishment of selected screening programmes in some of the districts of the Oxford Region in 1978 for young children. ${ }^{11}$ Since that time, patients have been screened by the district assessment clinics. Those who are diagnosed are diagnosed earlier, and receive refraction and occlusion therapy to eliminate ambylopia. Fewer children undergo hospital 
Table III Admission rates for each main diagnosis: number of people admitted per 10,000 population in each year

\begin{tabular}{|c|c|c|c|c|}
\hline Year & Cataract & Strabismus & Glaucoma & $\begin{array}{c}\text { Retinal } \\
\text { detachments } \\
\& \text { defects }\end{array}$ \\
\hline 1975 & 4.54 & 3.64 & 1.05 & 0.68 \\
\hline 1976 & 4.59 & 4.40 & 1.48 & 0.80 \\
\hline 1977 & 5.06 & 3.71 & 1.66 & 0.71 \\
\hline 1978 & 5.02 & 3.76 & 1.49 & 0.83 \\
\hline 1979 & 5.58 & 2.84 & 1.21 & 0.87 \\
\hline 1980 & 6.07 & 2.82 & 1.05 & 0.90 \\
\hline 1981 & 6.21 & 2.73 & 1.20 & 0.88 \\
\hline 1982 & 7.05 & 2.85 & 1.25 & 0.66 \\
\hline 1983 & 6.77 & 2.72 & 1.34 & 0.80 \\
\hline 1984 & 6.82 & 2.51 & 1.24 & 0.84 \\
\hline 1985 & 6.86 & 2.52 & 1.25 & 0.78 \\
\hline$\%$ of all cases & 34.6 & 18.4 & 7.6 & 4.7 \\
\hline $\begin{array}{l}\text { average annual } \\
\text { change }\end{array}$ & $+4.81 \%$ & $-5.21 \%$ & $-0.99 \%$ & $+0.68 \%$ \\
\hline$\chi_{1}^{2}$ & $293.21^{*}$ & $195.83^{*}$ & ns & ns \\
\hline $95 \%$ CI & $4.23 / 5.39$ & $-5.84 /-4.40$ & $-2.14 / 0.17$ & $-0.81 / 2.18$ \\
\hline
\end{tabular}

$\chi_{1}^{2}$ Chi Square Trend Analysis

${ }^{*} \mathrm{p}<0.001$

visits and the numbers of children requiring surgery for strabismus are reduced. As the number of districts served in this expanding programme has increased, the number of admissions with a diagnosis of strabismus and surgical procedures on the muscles of the eyeball has decreased.

The substantial increase in cataract admission rates in the elderly, which has occurred nationally as well as in Oxford,,$^{12}$ has implications for the use of resources, as cataract surgery requires more theatre space for more expensive surgery, and results in a longer hospital stay than does surgery for strabismus. In 1988, after the time period covered by this paper, day case cataract surgery was expanded, for selected patients, in a number of hospitals in the Oxford Region beyond the one hospital in which it was introduced in earlier years. ${ }^{1}$ This has reduced the pressure on inpatient services for this surgery.

We have shown increases in hospital admissions (both in multiple admissions per individual treated, and in numbers of people treated), no increase in emergency readmission rates, increases in the number of elderly treated, decreases in the number of children treated, and striking shifts in clinical casemix. These factors may be linked, perhaps multifactorially, with outpatient workload in ophthalmology (which is, of course, a major proportion of the total workload of this specialty), and with ongoing changes in clinical practice in ophthalmic services. In particular, community child screening programmes and altered perceptions of the elderly to these services have affected the workload in ophthalmology. With the likelihood of continuing changes in workload in ophthalmology, routine monitoring is merited.

The Unit of Clinical Epidemiology is part of the Department of Public Health and Primary Care, University of Oxford. The Unit is funded by the Department of Health, and the Oxford record linkage study is funded by the Oxford Regional Health Authority. Dr. Joyce Ferguson was supported through a post-Doctoral Fellowship from the National Health Research and Development Programme (Canada). The authors are grateful to Miss Catherine Wortham, Head Orthoptist, Hospital and Community Services, Oxfordshire Health Authority, for her clinical advice regarding this manuscript.

This study would not have been possible without the dedicated efforts of computing staff for the Oxford record linkage study and we thank Leicester Gill, Hugh Simmons, Glenys Bettley and Myfanwy Griffith.

\section{Appendix:}

\section{Diagnoses from the International}

Classification of Diseases:

retinal detachments and defects ICD-8 376, ICD-9 361- 
retinal detachment with retinal defect, retinoschisis and retinal cysts, serous retinal detachment, and retinal defects without detachment.

glaucoma ICD-8 375, ICD-9 365-

borderline glaucoma; open-angle glaucoma; primary angle-closure glaucoma; corticosteroid-induced glaucoma; glaucoma associated with congenital anomalies, with dystrophies and with systemic syndromes; glaucoma associated with disorders of the lens; and glaucoma associated with other ocular disorders.

cataract ICD-8 374, ICD-9 366-

infantile, juvenile and presenile cataract: senile cataract; traumatic cataract; cataract secondary to ocular disorders; and cataract associated with other disorders.

strabismus and other disorders of binocular eye movements ICD-8 373, ICD-9 378-

convergent concomitment strabismus, divergent concomitant strabismus, intermittent heterotropia, other and unspecified heterotropia, heterophoria, paralytic strabismus, mechanical strabismus, and other disorders of binocular eye movements.

\section{References}

${ }^{1}$ Goldacre MJ and Ingram RM: Changing workload in ophthalmology: some observations from routine statistics. Br Med J 1983; 286: 1560-61.
${ }^{2}$ Pollock RM. The health of the people of Oxford region. Oxford: Oxford Regional Health Authority, section 3.4, 1990.

${ }^{3}$ Cullinan TR. The epidemiology of visual disabilitystudies of visually disabled people in the community. University of Kent, Canterbury Health Services Research Unit Report No. 28, 1977.

${ }^{4}$ Collinan TR, Gould ES, Silver JH et al: Visual disability and home lighting. Lancet 1979; 1: 642-4.

${ }^{5}$ Goldacre MJ, Simmons H, Henderson J, Gill LE: Trends in episode based and person based rates of admission to hospital in the Oxford record linkage study area. Br Med J 1988; 296: 583-5.

${ }^{6}$ Acheson ED. Introduction. In: Textbook of medical record linkage (eds. JA Baldwin, ED Acheson, WJ Graham). Oxford: Oxford University Press, 1987.

${ }^{7}$ Henderson J, Goldacre MJ, Graveney MJ, Simmons $\mathrm{H}$. Use of medical record linkage to study readmission rates. Br Med J 1989; 299: 709-713.

${ }^{8}$ World Health Organization. Manual of the international statistical classification of diseases, injuries, and causes of death. Geneva: World Health Organization 1967.

${ }^{9}$ World Health Organization. Manual of the international statistical classification of diseases, injuries, and causes of death. Geneva: World Health Organization 1977.

${ }^{10}$ Department of Health and Social Security. Steering group on health services information (Chair: Mrs. E Korner): first report to the Secretary of State. London: HMSO, 1982.

${ }^{11}$ Kendall JA, Stayte MA, Wortham C: Ocular defects in children from birth to 6 years of age. Br Orthopt J 1989; 46: 3-6.

${ }^{12}$ Department of Health and Social Security and Office of Population Censuses and Surveys. Hospital In-Patient Enquiry. HMSO, annual. 